\title{
Ultrasound-Guided Aspiration for Relief of Pain Generated by Simple Ovarian Cysts

\begin{tabular}{|l|l|l|}
\hline B. & Benjamin & Caspi \\
\hline Y. & Yawn & Zalel \\
\hline S. & Samuel & Lurie \\
\hline U. & Uriel & Elchlal \\
\hline Z. & Zvi & Katz \\
\hline
\end{tabular}

Department of Obstetrics and Gynecology, Kaplan Hospital, Rehovot, Israel

\section{Key Words}

Ovarian cyst

Ultrasound

Abstract

Over a 2-year period, ultrasound-guided aspiration of painful, presumptively benign ovarian cysts was performed in 18 women $<40$ years old. Aspiration was performed either transvaginally (12 patients) or transabdominally ( 6 patients) depending on the cyst location. Neither anaesthesia nor analgesia were used, and all patients had immediate pain relief, and escaped immediate surgical intervention. None had complications or evidence of malignant cells on cytologic examination, and all were discharged within $24 \mathrm{~h}$ of the procedure. The recurrence rate within 1 year of the procedure was $11.1 \%$. The procedure appeared to be a good and safe alternative to surgery. S. Lurie, MD, Department of Obstetrics and Gynecology, Kaplan Hospital, 76100 Rehovot (Israel)

\section{Introduction}

To date, surgery has been the basic treatment for symptomatic and presumptively benign ovarian tumours [1,2]. Recently, in cases of twisted ovarian cysts, laparoscopic aspiration and unwinding the cysts has been suggested $[3,4]$. Laparotomy is thus prevented, with important implications for future fertility. Preservation of future fertility also motivated the introduction of ultrasoundguided puncture of 'simple' ovarian cysts $[5,6]$. In comparison with laparoscopic aspiration and unwinding of twisted ovarian cysts, ultrasound-guided puncture may mean even less risk of pelvic adhesions, and may additionally reduce morbidity associated with general anaesthesia. Until now, most of the published studies on ultrasound-guided aspiration of ovarian cysts were performed on persistent cysts. This preliminary study was undertaken in order to assess the possibility of escaping operative intervention in patients with painful simple ovarian cysts, that were clinically suspected to be incompletely or completely twisted.

Materials and Methods

This study was performed over a 2-year period (1987-1989). The criteria for the selection of patients appropriate for ultrasound-guided aspiration included symptomatology and ultrasonographic appearance. Only patients who would have otherwise undergone laparotomy because of the severity of the pain or peritoneal signs were included. Cysts had to be $<9 \mathrm{~cm}$ in diameter, unilateral, had to appear unilocular or with thin septa, and have regular borders considered to be benign. The presence of irregular borders, high echoge-nicity, papillae, solid 
areas, thick septa, or ascites were indications for exclusion. Eighteen consecutive patients aged 13-40 years (mean 28) were enrolled in the study.

The aspiration was performed either transvaginally (12 patients) or transabdominally (6 patients) depending on the cyst location. No anaesthesia or analgesia were used. For transabdominal aspiration, a 20-gauge spinal needle was used, while for the transvaginal route we used the 16gauge needle that is used for egg collection in the IVF programme. The aspirated fluid was examined for the presence of malignant cells.

The patients were followed up by ultrasonographic examination 1,3 and 12 months after the procedure. The examination was performed in the follicular phase of the menstrual cycle.

\section{Results}

All patients experienced complete pain relief at the end of the aspiration. There were no complications, and the patients were discharged within $24 \mathrm{~h}$ of the aspiration. The cysts ranged in size from 4 to $9 \mathrm{~cm}$ in diameter. The aspirated fluid was clear in 13 patients and bloody in 5 . All the cytologic analyses were negative for malignant cells.

Sixteen patients (88.9\%) were free of complaints during the follow-up period. There were no recurrent cysts on repeated ultrasonographic examinations and the patients did not need any additional treatment. The remaining two patients had a recurrent cyst. They eventually underwent a laparotomy: the histologic diagnoses were a corpus luteum cyst and a cystadenofibroma.

Discussion

We have described our experience with ultrasound-guided aspiration of a painful ovarian cyst in 18 women $<40$ years old. It appears to be a good and safe alternative to surgery, preserving ovarian function and potentially reducing the risk of pelvic adhesions. In women with clinical symptoms consistent with an incompletely or completely twisted ovarian cyst, some kind of extirpative treatment has to be considered. It is noteworthy that in our study all women escaped immediate surgical intervention. The recurrence rate within 1 year of the procedure was $11.1 \%$, which is lower than that reported in a previous study (23\%) [5]. There are, however, some important concerns with respect to the validity of the procedure. One is the ability of ultrasound to identify benign ovarian cysts. Using strict ultrasonographic criteria, benign cysts were accurately predicted in $96 \%$ of 185 patients in one study [7], and in 92\% of 180 patients in another [8]. In a further study, malignant masses were distinguished from benign lesions by transvaginal ultrasonography with a sensitivity of $100 \%$ in 143 patients, using a strict scoring system [9]. Hence, it is not unreasonable to rely on ultrasonographic examination, but the aspirated fluid should always be tested for the presence of malignant cells.

Another concern is the theoretic risk of'spilling' cancer cells into the peritoneal cavity and thus decreasing the patient's chances of survival. However, in a multivariate analysis of factors that affect the rate of relapse it was found that the rate of relapse is not influenced by tumour rupture [10]. Thus, the theoretic potential of tumour dissemination by iatrogenic rupture of a malignant cyst remains conjectural.

We conclude that in carefully selected patients with a painful ovarian cyst, ultrasound-guided aspiration can provide an alternative to laparotomy or operative lapa-roscopy. As more information becomes available, clinicians will have different options to manage simple painful ovarian cysts, each uniquely suited to a patient's fertility potential and the course of her disease. References 
Merril JL, Zaloudek C, Tavassoli FA, Kurman RJ: Lesions of the ovary; in Danforth DN, Scott JR (eds): Obstetrics and Gynecology, ed 5. Philadelphia, Lippincott, 1986, p 1112. Parker WH: Management of ovarian cysts by operative laparoscopy. Contemp Obstet Gyne-col 1991;36:4758.

Ben-Rafael Z, Bider D, Mashiach S: Laparo-scopic unwinding of twisted ischemic hemor-rhagic adnexum after in vitro fertilization. Fer-tilSteril 1990;53:569-571.

Shalev E, Rahav D, Romano S: Laparoscopic relief of adnexal torsion in early pregnancy. $\mathrm{Br} \mathrm{J}$ Obstet Gynaecol 1990;97:853-854. Granberg S, Crona N, Enk L, Hammarberg K, Wikland M: Ultrasound-guided puncture of cystic tumors in the lower pelvis of young women. J Clin Ultrasound 1989;17:107-Ill. De Crespigny LC, Robinson HP, Davoren RAM, Fortune D: The ‘simple’ ovarian cyst: Aspirate or operate? Br J Obstet Gynaecol 1989;96:1035-1039. Hermman UJ, Gottferid WL, Goldhirsh A: Sonographic patterns of ovarian tumors: Prediction of malignancy. Obstet Gynecol 1987; 69:777-781.

Granberg S, Norstrom A, Wikland M: Tumors in the pelvis as imaged by vaginal sonography. Gynecol Oncol 1990;37:224-229. Sassone AM, Timor-Trich IE, Artner A, West-hoff C, Warren W: Transvaginal sonographic characterization of ovarian disease: Evaluation of a new scoring system to predict ovarian malignancy. Obstet Gynecol 1991;78:70-76. Dembo A, Davy M, Stenwig A, Berle EJ, Bush RS, Kjorstad K: Prognostic factors in patients with stage I epithelial ovarian cancer. Obstet Gynecol 1990;75:263-273.

122

Caspi/Zalel/Lurie/Elchlal/Katz

Ultrasound-Guided Cyst Aspiration 